\title{
Study on micro extra deep drawing process with ultrahigh fluid pressure and press motion controls
}

\author{
Hideki Sato $^{1, a}$, Daiki Kondo ${ }^{1}$, Ken-ichi Manabe ${ }^{1}$, and Kuniyoshi Ito ${ }^{2}$ \\ ${ }^{1}$ Tokyo Metropolitan University, Department of Mechanical Engineering, 1-1, Minamiosawa, \\ Hachioji, Tokyo 192-0397, Japan \\ ${ }^{2}$ LLC) Micro Fabrication Laboratory, Seki-building 2-9-22 Myoujin, Hachioji, Tokyo 192-0046, \\ Japan
}

\begin{abstract}
A novel micro extra deep drawing process with ultrahigh fluid pressure and press motion controls are developed. A space between the blank and $1^{\text {st }}$ punch is made by the press motion at the $2^{\text {nd }}$ drawing stage and the ultrahigh pressure is applied so as to be disappeared this space. It can enhance a material flow into the die cavity because the ultrahigh pressure acts on the blank at side wall. In addition, a friction holding effect occurs, which prevents the thickness reduction at punch shoulder and side wall. Due to these mechanisms, the micro cup with aspect ratio of 2.0 can be successfully fabricated by micro extra deep drawing in FE simulation, although it cannot be fabricated by conventional micro deep drawing and micro hydromechanical deep drawing.
\end{abstract}

\section{Introduction}

Extra deep drawing has been developed as the special forming technique to fabricate the parts with high aspect ratio. It uses several forming principles such as, multi steps [1], counter and radial pressures [2], flange pressing [3], local heating and cooling [4], and super plasticity [5]. These technologies can achieve the high formability respectively. If these technologies can be scaled down to micro scale, it is useful to fabricate micro parts with high aspect ratio. However, when the dimension of part is scale down, there are several problems in micro scale to fabricate the micro parts with high aspect ratio using conventional micro deep drawing. It is difficult to fabricate the tiny tools and handle the tiny workpiece. The increase of friction force and the decrease of strength and ductility are resulted with scaling down to micro scale because of the tribological and grain size effects [6, 7]. These size effects cause the low formability in micro forming. Due to these difficulties in micro scale, no micro extra deep drawn cup except for micro cup with diameter of $0.5 \mathrm{~mm}$ and aspect ratio of 1.1 using micro redrawing process has been reported [8]. Thus, it is difficult to fabricate the micro parts with high aspect ratio using conventional micro forming techniques.

\footnotetext{
${ }^{\text {a }}$ Corresponding author: sato-hideki@ed.tmu.ac.jp
}

This is an Open Access article distributed under the terms of the Creative Commons Attribution License 4.0, which permits unrestricted use, distribution, and reproduction in any medium, provided the original work is properly cited. 


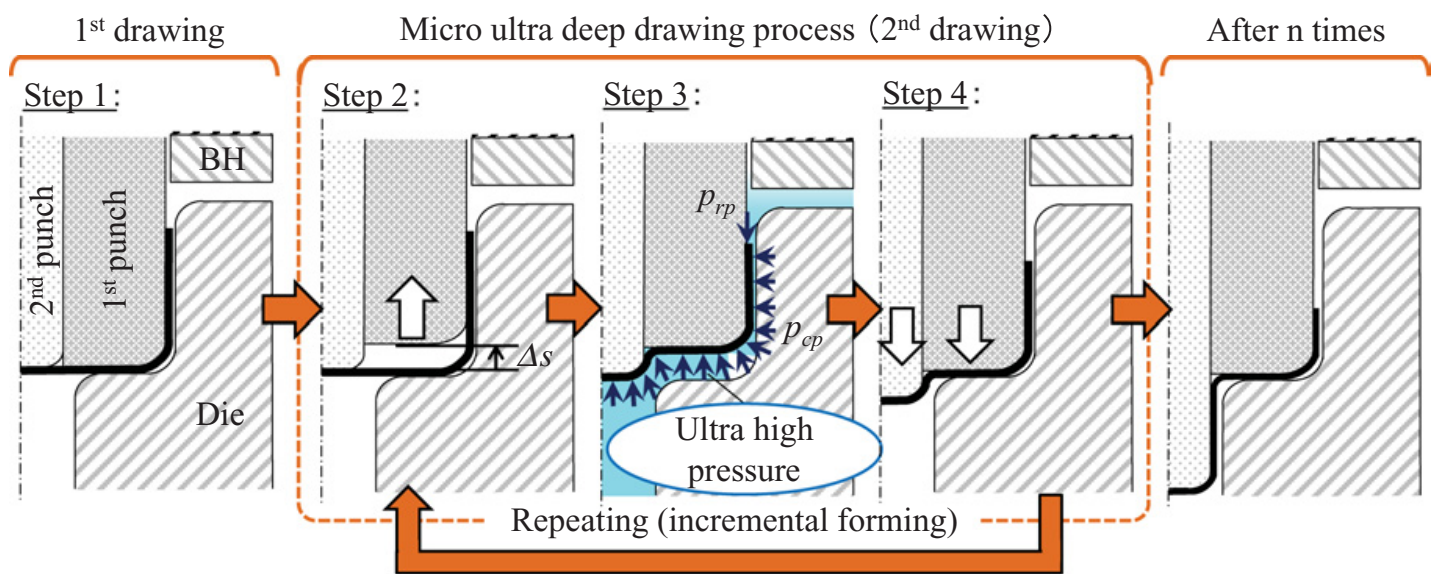

Figure 1. Forming process of micro extra deep drawing.

In conventional deep drawing, the blank is deformed by pulling force of the punch. The blank is subjected to the tensile stress during forming process and fracture occurs when the tensile stress reaches the tensile strength at punch shoulder part. Therefore, there is a limitation to improve the formability using conventional techniques. On the other hand, in extra deep drawing using flange pressing and aided friction force [9], the blank was deformed by the compression force. The compression force induces the material flow into the die cavity and deforms the blank without the tensile stress. Therefore, the fracture does not occur and the forming limit can be significantly improved. To use this forming deep drawing mechanism in micro scale, we propose and develop a novel micro extra deep drawing process using ultrahigh pressure and press motion controls. Using the micro extra deep drawing, the micro cup with large aspect ratio is fabricated and its forming mechanism is investigated using finite element (FE) simulation.

\section{Micro extra deep drawing process}

Figure 1 shows the micro extra deep drawing process. The newly proposed process is performed at the 2nd drawing stage. The 2 nd punch is inside of the 1 st punch to perform the 1 st and 2 nd drawings at the same axis. At stage 1, the 1st drawing is performed. At stage 2, the 1st punch is lifted up and the space is made between the 1st drawing and blank. At stage 3, the ultrahigh pressure is applied so as to be disappeared the space between the 1st punch and blank. At this stage, the blank flows into the inside and fits the punches. At stage 4, the 1st and 2nd punches go down. The blank thickness can be controlled by pressing force in this stage. These stages 2, 3 and 4 are regarded as 1 cycle and the long micro cup can be drawn by continuing several cycles.

\section{FE simulation}

The numerical analysis was carried out with an explicit dynamic FE code, LS-DYNA ver.971. The stainless steel foil (SUS304-H) of $50 \mu \mathrm{m}$ thickness was employed for FEM. For the mechanical properties, the young's modulus $E=197 \mathrm{GPa}$ and yield stress $\sigma_{y}=589 \mathrm{MPa}$ are used and a real stressstrain curve obtained by tensile test was input into FEM directly as shown in Fig. 2. The tooling dimensions used in micro extra deep drawing is listed in Table 1. The drawing ratios for 1st, 2nd drawing and total drawing ratio are $D R_{1}=1.8, D R_{2}=2.1$ and $D R=3.8$, respectively. The blank was 


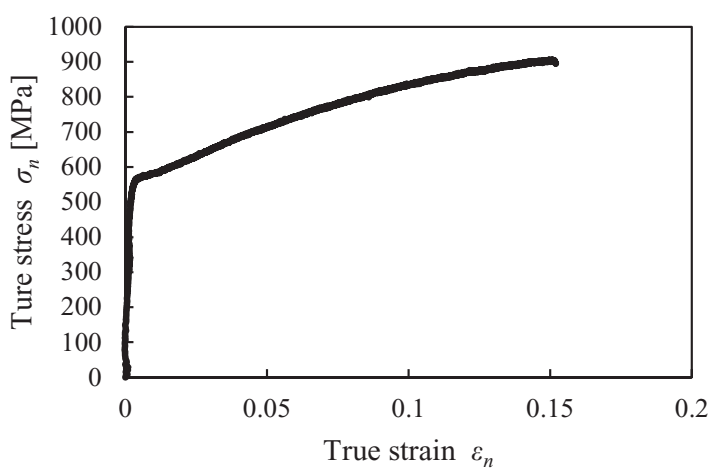

Figure 2. Stress strain curve of used material (SUS304).

Table 1. Tooling dimensions for micro extra deep drawing.

\begin{tabular}{|l|l|l|}
\hline \multicolumn{2}{|c|}{ Initial blank diameter $D_{0}[\mathrm{~mm}]$} & 1.700 \\
\hline \multirow{4}{*}{ Drawing punch } & 1st punch diameter $D_{P 1}[\mathrm{~mm}]$ & 0.944 \\
\cline { 2 - 3 } & 2nd punch diameter $D_{P 2}[\mathrm{~mm}]$ & 0.444 \\
\cline { 2 - 3 } & 1st punch corner radius $r_{p 1}[\mathrm{~mm}]$ & 0.160 \\
\cline { 2 - 3 } Drawing die & 2nd punch corner radius $r_{p 2}[\mathrm{~mm}]$ & 0.120 \\
\hline \multirow{5}{*}{ 1st die diameter $D_{d 1}[\mathrm{~mm}]$} & 1.000 \\
\cline { 2 - 3 } & 2nd die diameter $D_{d 2}[\mathrm{~mm}]$ & 0.500 \\
\cline { 2 - 3 } & 1st die corner radius $r_{d 1}[\mathrm{~mm}]$ & 0.200 \\
\cline { 2 - 3 } & 2nd die corner radius $r_{d 2}[\mathrm{~mm}]$ & 0.100 \\
\hline \multicolumn{2}{|c|}{ Clearance $C(=1.4 t)[\mathrm{mm}]$} & 0.028 \\
\hline
\end{tabular}

Table 2. Forming parameters for each forming method.

\begin{tabular}{|l|c|c|c|}
\hline & $\begin{array}{l}\text { Constant gap } \\
h[\mathrm{~mm}]\end{array}$ & $\begin{array}{l}\text { 1st punch displacement } \\
\Delta s[\mathrm{~mm}]\end{array}$ & $\begin{array}{l}\text { Counter and radial pressure } \\
p_{r p}, p_{c p}[\mathrm{MPa}]\end{array}$ \\
\hline Micro deep drawing & 0.022 & - & - \\
\hline Micro hydromechanical deep drawing & 0.022 & - & $p_{r p}=p_{c p}=100$ \\
\hline Micro extra deep drawing & - & 0.03 & $p_{r p}=p_{c p}=100$ \\
\hline
\end{tabular}

modeled as the solid of isotropic elastoplastic, and the tools were modeled as the shell of rigid body. The static and kinetic friction coefficients were set at $\mu_{s}=0.20, \mu_{d}=0.15$ between the blank and 1 st and 2 nd punches, and $\mu_{s}=0.005, \mu_{d}=0.003$ between the blank and die, respectively. To compare the formability, not only micro extra deep drawing but also the conventional micro deep drawing and micro hydromechanical deep drawing were carried out. In micro deep drawing and micro hydromehcanical deep drawing, the constant gap method was adopted. The forming parameters, constant gap $h$, punch displacement $\Delta s$, counter pressure $p_{c p}$ and radial pressures $p_{r p}$, were listed in Table 2.

\section{Results and discussion}

\subsection{Drawn cups}

Figure 3 shows the blank and cup shapes at the each stage of micro extra deep drawing. Through the 1st and the 2nd drawings, the micro cup with total drawing ratio of 3.8 can successfully be fabricated by micro extra deep drawing. Figure 4 shows the appearance of micro cups drawn by different forming methods. For the 2nd drawing of micro deep drawing and micro hydromechanical deep drawing, the local thinning occurs at 2 nd punch shoulder and the micro cup cannot be drawn. On the other hand, the long micro cup with aspect ratio of 2.0 can be successfully drawn in micro extra deep drawing. It 


\section{MATEC Web of Conferences}

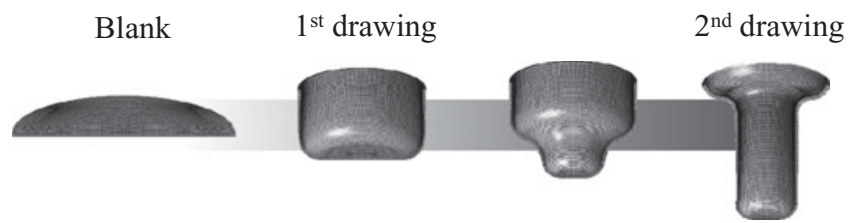

Figure 3. Blank and cup shapes at each stage of micro extra deep drawing.

\begin{tabular}{|c|c|c|c|}
\hline $\begin{array}{c}\text { Micro deep } \\
\text { drawing }\end{array}$ & $\begin{array}{c}\text { Micro deep } \\
\text { drawing }\end{array}$ & $\begin{array}{c}\text { Micro } \\
\text { hydromechanical } \\
\text { deep drawing }\end{array}$ & $\begin{array}{c}\text { Micro } \\
\text { extra deep } \\
\text { drawing }\end{array}$ \\
\hline $\begin{array}{c}\text { Aspect ratio } \\
H / D=0.6\end{array}$ & Fracture & Fracture & \\
\hline
\end{tabular}

Figure 4. Appearance of micro cups drawn by different forming methods.

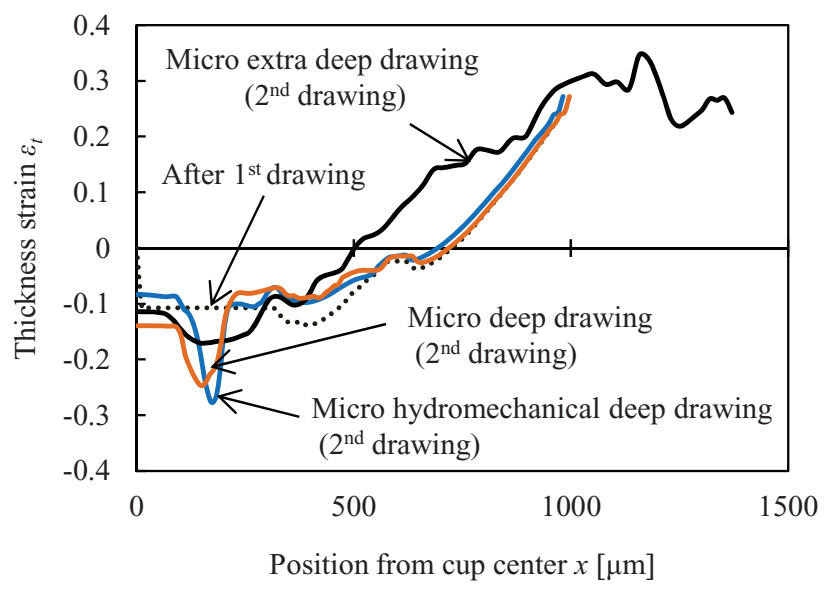

Figure 5. Comparison of thickness strain distribution for each forming method.

is because the thickness reduction at 2 nd punch is prevented in micro extra deep drawing although the thickness significantly decreases at the 2nd punch shoulder in conventional micro deep drawing and micro hydromechanical deep drawing as shown in Fig. 5. It was found that micro extra deep drawing can fabricate the micro cup with longer aspect ratio than conventional micro redrawing [8].

\subsection{Material flow in micro extra deep drawing}

Figure 6 shows the material flow of blank by applying the ultrahigh pressure in micro extra deep drawing. By applying the ultrahigh pressure to the space between the blank and 1st punch, the blank at 


\section{ICNFT 2015}

(a)

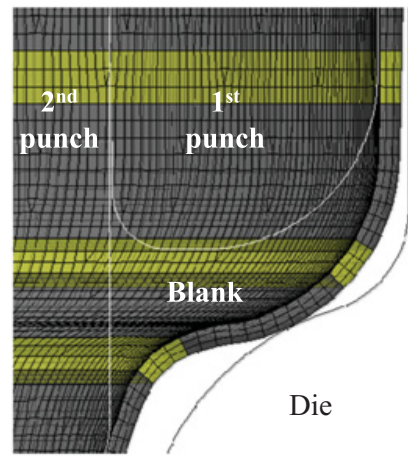

\section{Compression force}

(b) by radial pressure $\neg \downarrow$

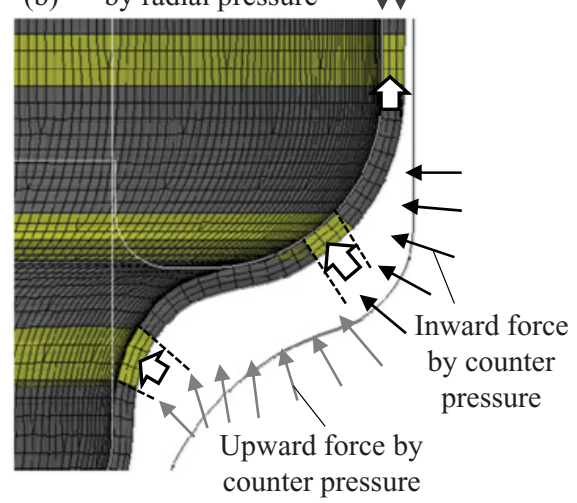

Figure 6. Material flow of the blank (a) before and (b) after applying the ultrahigh pressure.

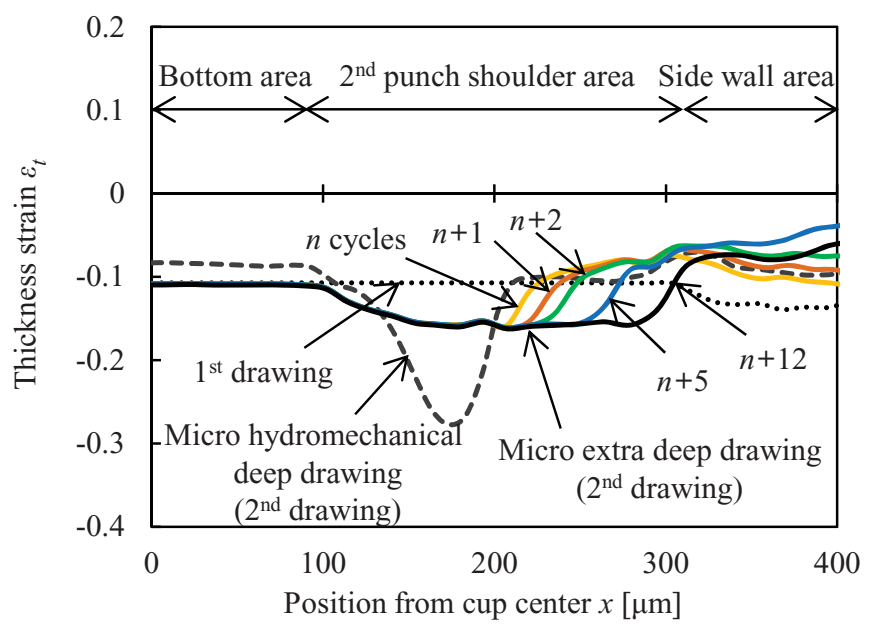

Figure 7. Change of thickness strain distribution near 2nd punch shoulder part in micro extra deep drawing process.

side wall of 2 nd punch and flange area flow into the inside. It shows that the application of ultrahigh pressure can enhance the material flow by an inward force by counter pressure. In contrast, at the side wall of 1 st punch, the blank goes up by an upward force by counter pressure. It prevents the material flow at side wall of 1 st punch unlike at flange area. These material flows are related with the upward force by counter pressure, inward force by counter pressure, and compression force by radial pressure. These forces can be varied by changing the pressurization, tooling dimension, and the 1st punch displacement. By adjusting these parameters, the appreciate material flow can be obtained.

\subsection{Friction holding effect in micro extra deep drawing}

Figure 7 shows the change of thickness distribution near the 2nd punch shoulder during micro extra deep drawing process. The thickness decreases at the blank which does not contact with the 2 nd punch. However, after the blank contacts with the 2nd punch, the thickness does not decrease. This behavior is called as the friction holding effect [2]. On the other hand, in micro hydromechanical deep drawing, 


\section{MATEC Web of Conferences}

the thickness significantly decreases at the 2nd punch shoulder. It seems that the friction holding force at 2 nd punch shoulder is not enough to prevent the thickness reduction. In the 2 nd drawing of micro hydromechanical deep drawing, the friction holding force occurs not only at the 2 nd punch shoulder but also the 1st punch shoulder. It increases the drawing resistance at flange area. In addition, the blank is deformed by the pulling force of punch in micro hydromechanical deep drawing. The blank at punch shoulder is subjected to the applied force during the forming process. Therefore, the applied force to blank becomes high and the fracture occurs. On the other hand, in micro extra deep drawing the blank is deformed by ultrahigh pressure which enhances the material flow. Therefore, the applied force to blank can be reduced. It is because that the friction holding effect can be obtained in micro extra deep drawing.

\section{Conclusion}

The objective of this research is to developed the micro extra deep drawing process using ultrahigh pressure and press motion controls to fabricate the long micro cup. In micro extra deep drawing, the space is made between the blank and the 1 st punch by press motion contorol, and the blank is deformed by applying the ultrahigh pressure toward the space. It can enhance the material flow into the inside because the ultrahigh pressure acts on the blank at side wall. Moreover, the friction holding effect can be obtained, which prevents the thickness reduction at punch shoulder and side wall. Due to these forming mechanism, the micro extra deep drawing can sucessfully fabricate the micro cup with the aspect ratio of 2.0 in FE simulation. It was shown that the micro extra deep drawing can exceed the aspect ratio of micro cup drawn by conventional micro redrawing.

This work was supported by JSPS KAKENHI Grant Number 26630369. The authors would like to thank JSPS for their financial support within the project.

\section{References}

[1] Y. Harada, Y. Maeda, M. Ueyama, I. Fukuda, Procedia Eng., 81 (2014), 819-824

[2] T. Nakagawa, K. Nakamura, H. Amino, J. Mater. Process. Technol., 71 (1997), 160-167

[3] T. Iizuka, The Intellectual Series 2013, Kyoto Institute of Technology (in Japanese), (2013), 118

[4] S. Yoshihara, H. Yamamoto, K. Manabe, H. Nishimura, J. Mater. Process. Technol., 143-144 (2003), 612-615

[5] H. Nishimura, Y. Kawakami, M. Miayagawa, Journal of JSTP (in Japanese), 16 (1975), 955-962

[6] U. Engel, Wear, 260 (2006), 265-273

[7] M.W. Fu, W.L., Mater. Design, 32 (2011), 4738-4746

[8] K. Manabe, T. Shimizu, H. Koyama, M. Yang, K. Ito, J. Mater. Process. Technol., 204 (2008), 89-93

[9] M.A. Hassan, R. Suengaga, N. Takakura, K. Yamaguchi, J. Mater. Process. Technol., 159 (2005), $418-425$ 